\title{
Conservation of biodiversity of highly important medicinal plants of India through tissue culture technology- a review
}

\section{Sudhir Sharma ${ }^{1 *}$, Neelima Rathi ${ }^{1}$, Barkha Kamal $^{2}$, Dipika Pundir ${ }^{3}$, Baljinder Kaur ${ }^{4}$ and Sarita Arya ${ }^{4}$}

\author{
${ }^{1}$ Tissue Culture Discipline, Botany Division, Forest Research Institute, Dehradun \\ (Uttarakhand)-248006-INDIA \\ ${ }^{2}$ S.B. S. PG College of Biomedical Science, Dehradun (Uttarakhand)-INDIA \\ ${ }^{3}$ SAI Institute of Paramedical and Allied Sciences, Dehradun (Uttarakhand)-INDIA \\ ${ }^{4}$ Forest Genetics and Tree Breeding Division, Arid Forest Research Institute, Jodhpur \\ (Rajasthan)-342005-INDIA \\ Author for correspondence: sudhirfri2007@gmail.com, Contact no. +919927832700

\section{ABSTRACT}

According to the Red List of threatened species 44 plant species are critically endangered, 113 endangered and 87 vulnerable (IUCN, 2000). Many medicinal plants are also in trouble from over harvesting and destruction of habitat. Population growth, urbanization and the unrestricted collection of medicinal plants from the wild is resulting in an over-exploitation of natural resources. Therefore, the management of traditional medicinal plant resources has become a matter of urgency. An ever increasing demand of uniform medicinal plants based medicines warrants their mass propagation through plant tissue culture strategy. Tissue culture technology is potent and has opened extensive areas of research for biodiversity conservation. Tissue culture protocols have been developed for a wide range of medicinal plants, which includes endangered, rare and threatened plant species. Some of these medicinal plants are Saussaurea lappa, Picorrhiza kurroa, Ginkgo biloba, Swertia chirata, Gymnema sylvestre, Tinospora cordifolia, Salaca oblonga, Holostemma, Celastrus paniculata,. Oroxylum indicum, Glycyrrhiza glabra, Tylophora indica, Bacopa mooniera, Rauwolfia serpentina.

Keywords: Red list, Endangered, Medicinal Plants, Plant Tissue Culture, Tinospora, Bacopa, Rauwolfia.

\section{*Present Address:}

Research Scientist (R\&D), Department of Forest (Plantation), Star Paper Mills Limited, Saharanpur (Uttar Pradesh)-247001, INDIA

\section{INTRODUCTION}

In view of the tremendously growing world population, increasing anthropogenic activities, rapidly eroding natural ecosystem, etc the natural habitat for a great number of herbs and trees are dwindling. Many of them are facing extinction. To cope up with alarming situation, the recent exciting developments in biotechnology have come as a boon. One of them is the use of plant tissue culture technique. Most of the plant raised through seeds are highly heterozygous and show great variations in growth, habit and yield and may have to be discarded because of poor quality of products for their commercial release. Likewise, majority of the plants are not amenable to vegetative propagation through cutting and grafting, thus limiting multiplication of desired cultivars. Moreover many plants propagated by vegetative means contain systemic bacteria, fungi and viruses which may affect the quality and appearance of selected items. In recent years, tissue culture has emerged as a promising technique to obtain genetically pure elite populations under in vitro conditions rather than have indifferent populations. Tissue culture has now become a well established technique for culturing and studying the physiological behavior of isolated plant organs, tissues, cells, protoplasts and even cell organelles under precisely controlled physical and chemical conditions. Most of the medicinal plants either do not produce seeds or seeds are too small and do not germinate in soils. Thus mass multiplication of disease free planting material is a general problem. In this regard the micropropagation holds significant promise for true to type, rapid and mass multiplication under disease free 
Agric. Biol. J. N. Am., 2010, 1(5): 827-833

conditions. Besides, the callus derived plants exhibit huge genetic variation that could be exploited for developing superior clones/varieties particularly in vegetatively propagated plant species.

In terms of the number of species individually targeted, the use of plants as medicines represents by far the biggest human use of the natural world. Plants provide the predominant ingredients of medicines in most medical traditions. There is no reliable figure for the total number of medicinal plants on Earth, and numbers and percentages for countries and regions vary greatly (Schippmann et al., 2002). Estimates for the numbers of species used medicinally include: $35,000-70,000$ or 53,000 worldwide (Schippmann et al., 2002); 10,00011,250 in China (He and Gu, 1997; Pei, 2002; Xiao and Yong, 1998); 7500 in India (Shiva, 1996); 2237 in Mexico (Toledo, 1995); and 2572 traditionally by North American Indians (Moerman, 1998).

The United Nations Conference on Environment and Development (UNCED), held recently at Rio de Janeiro, Brazil helped to place the loss of biodiversity and its conservation on the global agenda. Resulting in biodiversity becoming a household wood. Biodiversity is a new term for species-richness (plants, animals, microorganisms) occurring as an interacting biotic component of an ecosystem in a given area.

\section{CURRENT STATUS OF BIODIVERSITY OF IMPORTANT MEDICINAL PLANTS IN INDIA:} Medicinal plants as a group comprise approximately 8000 species and account for about $50 \%$ of all the higher flowering plant species of India. Millions of rural mass use medicinal plants. In recent years the growing demand for herbal products has led to a quantum jump in volume of plant material traded within and outside the country. Very small proportions of the medicinal plants are lichens, ferns, algae etc; the majority of the medicinal plants are higher plants. Though India has rich biodiversity and one among the twelve mega diversity centers, the growing demand is putting a heavy strain on the existing resources causing a number of species to be either threatened or endangered category. About $90 \%$ of medicinal plants used by industries are collected from the wild. While over 800 species are used in production by industry, less than 20 species of plants are under commercial cultivation. Over $70 \%$ of the plant collections involve destructive harvesting because of the use of parts like roots, bark, wood, stem and the whole plant in case of herbs. This poses a definite threat to the genetic stocks and to the diversity of medicinal plants. Recently some rapid assessment of the threat status of medicinal plants using IUCN designed CAMP methodology revealed that about 112 species in southern India, 74 species in Northern and Central India and 42 species in the high altitude of Himalayas are threatened in the wild.

Rauwolfia Serpentina: Rauwolfia serpentina, also known as Rauwolfia, Indian Snakeroot and Sarpagandha that means "root of the snake". In traditional medicine system, it has been used for treating snake bite. This herb is highly effective in the treatment of high blood pressure. It is also very useful in mental disorders like insanity, mental illness and traumas. It is equally effective in treating insomnia because of its sedative properties. It has found also useful for Hysteria and Urticaria. According to Ayurveda it is the best among all anti-hypertensive drugs

Glycyrrhiza Glabra: It was one of the most widely known medicines in ancient history, and records of its use include Assyrian tablets of around 2000 BC and Chinese herbals of the same period. Theophrastos of Lesbos, writing in the fourth century BC wrote that it has the property of quenching thirst if one holds it in the mouth'. Dioscorides gave the plant its botanical name (Greek glukos $=$ sweet, riza $=$ root $)$. Its 13 th century English name was Lycorys, a corruption of glycyrrhiza.. Liquorice (Glycyrrhiza glabra) has long been used for both culinary and medical purposes. Used for flavoring and sweetening candies and medical remedies, licorice also has potent effects of its own, particularly for ulcers and adrenal insufficiencies. It is also used for asthmatic coughs, as an antispasmodic and ulcer remedy, and to cool 'hot' conditions.

Salacia Oblonga: Salacia oblonga is a woody plant found in the forests of Sri lanka and India. The Roots and stems of Salacia oblonga have been used extensively in Ayurveda and traditional Indian Medicine for the treatment for Diabetes. Salacia oblonga contains two potent a-Glucosidase inhibitors: Salicinol and Kotalanol. Major use of Salacia oblonga is in Diabetes. Superior in terms of safety compared to chemically synthesized products, Salacia oblonga is an effective anti-diabetic agent. Herbs used in traditional Indian medicine to treat diabetes seems to lower blood sugar and insulin levels in a manner similar to prescription drugs, a new study reports. Researchers gave extracts of the herb Salacia oblonga to 39 healthy adults, and the results were promising. The largest dose of the herb extract 1,000 milligrams-decreased insulin and blood glucose levels by 29 and 23 percent, respectively. "These kinds of reductions are similar to what we might see with prescription oral medications for people with diabetes," said Steve Hertzler, a study 
Agric. Biol. J. N. Am., 2010, 1(5): 827-833

co-author and an assistant professor of nutrition at Ohio State University. Salacia oblonga, which is native to regions of India and Sri Lanka, binds to intestinal enzymes that break down carbohydrates in the body.

Holostemma Ada-Kodien: The botanical name of jivanti is Holostemma ada-kodien (Synonym Leptadenia reticulate, $\mathrm{W} \& \mathrm{~A}$ ) and it belongs to family Asclepiadadeae. From the plant, stigma sterol and tocopherols were isolated. From the stem and leaves - hentriacontanol amyrin, amyrin, stigmasterol and sitosterol were also isolated. From the roots - lupeol, amyrin, sitosterol, alanine, aspartic acid, glycine, serine, threonine and valine have been isolated. Jivanti is sweet in taste, sweet in the post digestive effect and has cold potency. It alleviates all the three doshas, namely, vata, pitta and kapha. It possesses light and oily attributes. It is a rejuvenative, heart (caksusya and hrdya). It is used in diseases like fever, tuberculosis, burning sensation of the body and raktapittal. Mainly the roots and the whole plant are used for medicinal purposes. Externally the paste of its leaves and roots alleviate oedema due to vitiation of pitta dosa. The herb is beneficial for external use in various skin diseases, wounds and inflammation of the skin.

Picrorhiza Kurroa: Kutki or Picrorhiza Kurroa is a herbal medicinal plant from Scrophulariaceae family. It is also known as hellbore, katuka, kurri, Katuko, Kuru, Katukarogani. It is found in Himalayan region in India. This herbal medicine has shown effective therapeutic action in liver disorders. The crude extract of plant shows good results in liver damage caused by carbon tetrachloride, paracetamol, galactosamine and alcohol. According to Ayurveda the plant has utility as laxative, liver-stimulant, appetite and stimulant, febrifuge. The plant is also beneficial in bronchial asthma and epidemic jaundice. It is also used to ease stomachache, and is believed to promote appetite. The herb is also effective in 'Kapha'disorders, billow fever, urinary discharge, hiccup, blood troubles, burning sensations and leucoderma.

Saussurea Lappa: Saussurea lappa is a tall, robust perennial Herb; leaves simple, large pubescent, heart shaped radical leaves with long petiole while cauline leaves are short stalk or half stem clasping. Inflorescence, capitulum or flowering head. Each capitulum surrounded by involucral bracts. Flowering heads are born in the top of the stem. Fruits, achene's. The roots have a pungent taste and a characteristic fragrant aromatic odour. The species grow on moist, open slopes between the altitudes of 2,600 to $3,600 \mathrm{~m}$, surrounding the valleys at the upper limits of tree growth. Its seedlings seem to prefer steep slopes with rich porous soil and a cool humid climate, but low rainfall. The genus Saussurea has many endemic species in Hindukush, Himalayan region. The species is mainly confined to Kashmir. In the northern areas, it is confined to Astore and Minimerg forest ranges. The most important locations where these species grow wild include Kalapani, Kamari and Thanknala, Mapno and Kilshai where this species is found growing in betula forests on hill slopes at a height of 2438-3657 meters in Himalayas. In Pakistan this species is found in Kaghan and Azad Kashmir. Roots is tonic, stomachic, stimulant, carminative, used for asthama, diuretic, antiseptic, cough, cholera, aphrodisiac, anthelmintic and also used to insecticide, pesticide. The roots are highly aromatic used in perfumeries, also used for skin diseases.

Locally it is used against the heart diseases of cattle and for toothache. The powdered roots are sprinkled over crops as insecticides. Externally the roots are used as an ointment or powder for the treatment of maggot-infested wound.

Celastrus Paniculatis: Celastrus paniculatis is a shrub used in Ayurdevic medicine in India. Various properties are attributed to the aerial parts of the plant, but we will deal here primarily with the seeds and the oil expressed from them. Celastrus paniculatis seeds and oil have long been regarded in India as beneficial to the intellect and memory. The seeds are hot, bitter, dry, acrid, appetizer, emetic expectorant, sodorific, liver tonic, aphrodisiac, stimulant, powerful brain tonic, stimulate intellect and sharpen memory, cure joint pain, paralysis, rheumatism, weakness; seed oil enriches the blood, cures abdominal complaints, stomachic, tonic, treats cough, asthma, leprosy, headaches, leucoderma. Seeds used externally on foul, indolent ulcers and scabies from seeds an oil is obtained. It is said to be excellent for beri-beri.

Bacopa Monnieri: Bacopa monnieri is a very popular herb in India for longevity and mental function. It is used to decrease fatigue and depression, and to stimulate the sex drive. It energizes the central nervous system, and aids the circulatory system, soothes and minimizes varicose veins and helps to minimize scarring. It is also useful in repairing skin and connective tissues and smoothing out cellulite. 
Agric. Biol. J. N. Am., 2010, 1(5): 827-833

It is generally considered an Ayurvedic "age tonic" restoring youth and vitality. Brahmi has been used by Ayurveda in India for almost 3000 years. The Ayurvedic treatise, the Charaka Samhita (100A.D.), recommends Brahmi in formulations for a range of mental conditions including anxiety, poor cognition and lack of concentration. In India, Brahmi is currently recognized as being effective in the treatment of mental illness and epilepsy.

Oroxylum Indicum: The botanical name of syonaka is Oroxylum indicum and it belongs to family Bignoniaceae. Baicalein, its 6-glucuronide and 7glucuronide, scutellarein, its 7- glucoronide isolated from leaves and stem bark. In addition, oraxylin A, chrysin and scutellarine -7 - rutinoside isolated from stem bark. Prunetin and sitosterol isolated from heartwood. A new flavone glucuronide - oroxindin isolated from seeds and characterized. The seed oil contains caprylic, lauric, myristic, palmitic, palmotoleic, stearic, oleic and linoliec acids. Baicalein -7-O gentiobioside isolated from seeds of Nepalese plant. Syonaka is astringent and bitter in taste, pungent in the post digestive effect and has cold potency. It alleviates all the three doshas. It possesses light and dry attributes. It is used in rheumatic disorders, diarrhea, cough, diabetes and cystitis. The skin of roots of syonaka is used for medicinal purpose, both, externally as well as internally. Used externally as a paste of its skin of roots, it dries up the discharges and promotes the wound healing. The tub bath with its decoction relieves the swelling and pain in rheumatic disorders. The medicated oil of syonaka in sesame oil base instilled into ears mitigates the pain in otitis. The decoction of its sroot-skin is an effective gargle in stomatitis. The root skin is also useful in dressing the wounds in soft chancre (upadamsa). Internally, syonaka is a panacea for arthritis and rheumatism. The decoction of the roots is commonly used for arthritis. In diarrhea and dysentery the decoction combined with mocarasa (gum of samali Bombax malabaricum). It is given along with honey. Syonaka also stimulates appetite, improves digestion and is vermicidal. It digests the ama from circulation, promotes diuresis and ameliorates cystitis. It also promotes diphoresis, hence, beneficial in fever. As it causes constipation, it is better followed by castor oil. Syonaka siddha ghrta is given internally, as well as enema (basti) in prolapse of the rectum and proctitis. In vata disorders due to obstruction of the channels, arthritis, rheumatic fever etc., Syonaka relieves the pains and alleviates vata dosha. Syonaka is salutary in cough, asthma and hiccup due to kapha. Syonaka relieves the pains and alleviates vata dosha. Syonaka is salutary in cough, asthma and hiccup due to kapha.

Tylophora indica (burm. F.) Merill.: It is generally found in the plains, forests, and hilly slopes and outskirts of the forest. Forms dense patches in the forest in moist and humid conditions in open hill slopes and narrow valleys, also cultivated for its medicinal uses. The plant Shows stunted growth in the areas with lesser rainfall. It will on a wide range of well drained soils prefer sandy localities. It is traditionally used as a folk remedy in certain regions of India for the treatment of bronchial asthma, inflammation, bronchitis, allergies, rheumatism and dermatitis. Apart from the above, it also seems to be a good remedy in traditional medicine as antipsoriasis, seborrhea, anaphylactic, leucopenia and as an inhibitor of the Schultz-Dale reaction.

\section{Tinospora cordifolia}

Tinospora cordifolia is commonly known as Guduchi is a famous plant of traditional use and also a powerful rasayana mentioned in Indian ayurvedic literature. It is considered as a bitter tonic and powerful immuno modulator. Guduchi is very much useful to enhance memory. Guduchi is a perennial plant of weak and fleshy stem found throughout the India. The aerial roots that arise from the stem are thread like. The leaf is heart shaped and smooth. The flowers are yellowish in colour emerges in bunch in rainy season. The fruits of guduchi are pea like which are seen in winter in India. Guduchi acts as a diuretic and found to be effective against renal obstruction like calculi and other urinary disorders. Guduchi acts as a memory booster, develops intelligence, and promotes mental clarity. It is described as one of the Medhya Rasayana (mental rejuvenative) in the Charak Samhita (The oldest and most potent book of ayurvedic medicine). Guduchi is regarded as a liver protector. Guduchi is considered helpful in eye disorders as a tissue builder and promotes mental clarity. The stem of guduchi is used in general debility, dyspepsia and urinary diseases. Guduchi is anti-pyretic and act as a tonic after fever, also has action against alternative fever like Malaria.

\section{Ginkgo biloba}

Ginkgo (Ginkgo biloba) also known as the Maiden hair tree after Adiantum, is a unique species of tree with no close living relatives. The ginkgo is classified in its own division, the Ginkgophyta, comprising the single class Ginkgoopsida, order Ginkgoales, family Ginkgoaceae, genus Ginkgo. It is the only extant species within this group. It is one of the best-known 
examples of a living fossil, because Ginkgoales other than G. biloba are not known from the fossil record after the Pliocene. Extracts of Ginkgo leaves contain flavonoid glycosides and terpenoids (ginkgolides, bilobalides) and have been used pharmaceutically. Ginkgo supplements are usually taken in the range of 40-200 mg per day. Recently, careful clinical trials have shown Ginkgo to be ineffective in treating dementia or preventing the onset of Alzheimer's Disease in normal people. Ginkgo has many alleged no tropic properties, and is mainly used as memory and concentration enhancer, and anti-vertigo agent. However, studies differ about its efficacy. The largest and longest independent clinical trial to assess ginkgo biloba's ability to prevent memory loss has found that the supplement does not prevent or delay dementia or Alzheimer's disease.

\section{Swertia chirata}

It is found is in the temperate Himalayas at an altitude of 1,200-3,000m from Kashmir to Bhutan and in the Khasi hills in Meghalaya at a height of 1,200$1,500 \mathrm{~m}$. According to Ayurveda, this herb is a bitter tonic, stomachic. It is useful in liver disorders, eyes, heart. It is an excellent remedy for a weak stomach, especially when this gives rise to nausea, indigestion and bloating and it has also been shown to protect the liver. It is best known as the main ingredient in Mahasudarshana churna, a remedy containing more than 50 herbs. It also contains xanthones which are reputedly effective against malaria and tuberculosis, and also amarogentin, a glycoside that may protect the liver against carbon tetrachloride poisoning. The whole plant is an excellent drug for intermittent fevers, skin diseases intestinal worms, bronchial asthma, burning of the body, regulating the bowels. The root of the plant is useful in checking hiccups and vomiting. It is used in the liquor industry as a bitter ingredient.

\section{Andrographis paniculata}

It is a principal herb in the domestic medicine known as 'Alui', which is given to infants. Both in Ayurveda and Unani, it is confused with 'Chitetta' (Swertia chirata), but both are different plants. It is widely available in Arabia. It is given for fever along with several herbs. It was advertised in England as a substitute for quinine. For centuries, the Ayurvedic practitioners of India have used the roots and leaves of the herb Andrographis paniculata to treat ailments ranging from poor digestion to hepatitis. In the Chinese medical tradition, the plant has been used to treat everything from gastrointestinal complaints to throat infections. Although some early scientific studies suggested that andrographis has a direct antimicrobial action, the weight of clinical evidence now shows that the real value of this ancient herb is as a stimulant for the immune system.

\section{IN VITRO CONSERVATION STRATEGIES USED FOR THE PROPAGATION}

Micropropagation/Clonal propagation techniques using shoot tip and nodal segments are must for mass-scale multiplication and conservation of an endangered or threatened and medicinally important species within short period and limited space. The plants produced from this method are true to type. Propagation through tissue culture provides solution for mass propagation of plants in general and threatened plants in particular. There is a need to conserve plants with medicinal values. Due to ever growing demand, the availability of medicinal plants to the pharmaceutical companies is not enough to manufacture herbal medicines. The powerful techniques of plant cell and tissue culture, recombinant DNA and bioprocessing technologies have offered mankind a great opportunity to exploit the medicinal plants under in vitro conditions.

Micropropagation: In clonal propagation, plants are multiplied using nodal segments and shoot meristems as explants. For rapid in vitro clonal propagation of plants, normally dormant axillary buds are induced to grow into multiple shoots by judicious use of growth regulators cytokinins and or auxin and cytokinin combinations. Shoot number increases logarithmically with each subculture to give greatly enhanced multiplication rates. As this method involves only organized meristems, hence it allows recovery of genetically stable and true to type progenies (Murashige, 1974; Hu and Wang, 1983).

Organogenesis: For the regeneration of a whole plant from a cell or from a callus mass cytodiffrentiation is not enough and there should be differentiation leading to organogenesis. This may occur through shoot bud differentiation (organogenesis) or through somatic embryogenesis. In the former, shoot buds (monopolar structures) are formed while in the later, somatic embryos (bipolar structures) are formed both leading to regeneration of whole plant. Callus mediated organogenesis depends on various factors. The type of callus, growth regulators used for induction of callus and also callus developed from the type of explant. The cells, although undifferentiated, contain all the genetic information present in parent plant. By suitable manipulation of growth regulators and contents of the 
medium, it is possible to initiate the development of roots, shoots and complete plant from callus cultures.

Somatic Embryogenesis: Somatic embryogenesis is the process of formation of embryo like structure from somatic tissue. The somatic embryo may be produced either directly on the explant or indirectly from callus or cell suspension culture. For the first time, Haccius (1978) defined somatic embryogenesis as a non-sexual developmental process, which produces a bipolar embryo from somatic tissue. The first report of plantlet regeneration via in vitro somatic embryogenesis was in Daucus carota (Reinert, 1958; Table-1: In vitro cultured important medicinal plants.
Steward et al., 1958). This pathway has offered a great potential for the production of plantlets and its biotechnological manipulation. In addition to the development of somatic embryos from sporophytic cells, embryos have been induced from generative cells such as in the classic work of Guha and Maheshwari (1964) with Datura innoxia microspores.

Tissue culture technique has been used successfully for in vitro mass propagation of various medicinal plants (Table. 1).

\begin{tabular}{|l|l|l|l|}
\hline Plant species & Explants & Nature of Response & Reference \\
\hline Bacopa monnieri & $\begin{array}{l}\text { Leaf explants \& Nodal } \\
\text { segments }\end{array}$ & Mass propagation & Mohapatra and Rath (2005) \\
\hline Calastrus paniculatus & Nodal segments & Shoot culture & Sood \& Chouhan (2009) \\
\hline Clitoria ternatea Linn & Nodal segments & Shoot culture & G.R. Rout (2005) \\
\hline Ginkgo biloba & Apical \& Nodal segments & Shoot culture & Tommasi \& Scaramuzzi (2004) \\
\hline Glycyrrhiza glabra & Nodal segments & Axillary bud culture & Vadodaria et al (2007) \\
\hline Gymnema sylvestre & Seeds & Seed culture & Komalavalli \& Rao (2000) \\
\hline Holostemma ada-kodien & Nodal segments & Bud culture & Martin (2002) \\
\hline Oroxylum indicum & Nodal segments & Shoot culture & Dalal \& Rai (2004) \\
\hline Picrorhiza kurroa & Nodal segments & Mass propagation & Martin et al (2006) \\
\hline Saussurea lappa & Shoot tip & Shoot culture & Johnson et al (2007) \\
\hline Swertia chirata & Shoot tip & Shoot culture & Balaraju et al (2009) \\
\hline Tylophora indica & Nodal segments & Mass propagation & $\begin{array}{l}\text { Faisal et al (2007), Sharma \& } \\
\text { Chandel (1992) }\end{array}$ \\
\hline Tinospora cordifolia & & Mass propagation & Gururaj et al (2007) \\
\hline
\end{tabular}

\section{ACKNOWLEDGEMENTS:}

Thanks are also due to Dr. I.D. Arya, Senior Scientist- $F$ who reviewed this manuscript and gave useful suggestions during the discussion and preparing of present manuscript.

\section{REFERENCES}

Balaraju, K., Agastin, P. and Ignacimuthu, S. (2009) Micropropagation of Swertia chirata Buch- Hams. Ex Wall: a critically endangered medicinal herb. Acta Physiologia Plantarum. 31(3): 487-494.

Bhatt, R., Arif. M., Gaur, A.K. and Rao, P. B (2008) Rauwolfia serpentine: Protocol optimization for in vitro propagation. African Journal of Biotechnology. Vol 7 (23), pp. 4265-4268.

Chaturvedi, H. C. (1979) Tissue culture of economic plants in progress in plant research, vol 1 , edited by $\mathrm{T}$. $\mathrm{N}$. Khoshoo \& P. K. Nair (Today and Tomorrow's printers and Publishers, New Delhi) 265.
Dalal, N. V. and Rai, V. R. (2004) In vitro propagation of Oroxylum indicum Vent. A medicinally important forest tree. Journal of Forest Research. 9(1): 61-65.

Faisal, M. and Anis, M. (2003) Rapid mass propagation of Tylophora indica via leaf callus culture. Plant Cell Tissue Organ Culture, 75(2): 125-129.

Faisal, M., Ahmad, N. and Anis. M. (2007) An efficient micropropagation system for Tylophora indica: an endangered medicinally important plant. Plant Biotechnology Reports. 1(3): 155-161.

Guha, S. and Maheshwari, S.C. (1964) In vitro production of embryos from anthers of Datura. Nature. 204: 497.

Gururaj, H. B., Giridhar, P. and Ravishankar, G. A. (2007). Micropropagation of Tinospora cordifolia (Willd.) Miers ex Hook. F \& Thoms: a multipurpose medicinal plant. Current Science. 92(1):23-26.

Haccius, B. (1978) Question of unicellular origin of zygotic embryos in callus cultures. Phytomorphology. 28: 7481.

He, S. A. and Gu, Y. (1997) The challenge for the 21st Century for Chinese botanic gardens. In : Touchell, 
D.H. and Dixon, K.W. (Eds.). Conservation into the 21st Century, Proc. 4th International Botanic Gardens Conservation Congress, Kings Park and Botanic Garden, Perth, Australia, pp. 21- 27.

Hu, C. Y. and Wang, P.J. (1983) Meristem shoot tip and bud cultures. In: Evans, D.A., Sharp, W.R., Ammirato, P.V. and Yamada, Y. (Eds.). Handbook of Plant Cell Culture, Vol. 1. Macmillan, New York. Pp 177-227.

Johnson, T. S., Narayan, S. B. and Narayana, D. B. A. (1977) Rapid in vitro propagation of Saussurea lappa, an endangered medicinal plant, through multiple shoot cultures. In vitro cellular and developmental biology. 33(2): 128-130.

Komalavalli, N. and Rao, M. V. (2000). In vitro micropropagation of Gymnema sylvestre- A multipurpose medicinal plant. Plant Cell, Tissue and Organ Culture. 61(2): 97-105.

Martin, K. P. (2002) Rapid propagation of Holostemma ada-kodien Schult., a rare medicinal plant through axillary bud multiplication and indirect organogenesis. Plant cell Reports, 21: 112-117.

Martin, G., Geetha, S. P., Raja Sudhakaran, S., Raghu, A. V., Balachandran I., Ravindran, P. N. (2006) An efficient micropropagation system for Celastus paniculatus Willd. A vulnerable medicinal plant. Journal of Forest Research, 11(6): 461-465.

Moerman, D.E. (1998) Native North American food and medicinal plants: epistemological considerations. In: Prendergast, H.D.V., Etkin, N.L., Harris, D.R. and Houghton, P.J. (Eds). Plants for food and medicine. Proc. Joint Conference of the Society for Economic Botany and the International Society for Ethno pharmacology, London, 1-6 July 1996, Royal Botanic Gardens, Kew, UK, pp. 69-74.

Mohapatra, H. P. and Rath, S. P. (2005) In vitro studies of Bacopa monnieri: An important medicinal plant with reference toits biochemical variations. Indian Journal of Experimental Biology. 43(4): 373-376.

Murashige, T. (1974) Plant propagation through tissue cultures. Ann. Rev. Plant Physiol. 25: 135-166.

Pei Shengji. (2002) A brief review of ethnobotany and its curriculum development in China. In : Shinwari, Z.K., Hamilton, A. and Khan, A.A (Eds.). Proceedings of a workshop on Curriculum Development in Applied Ethnobotany, Nathiagali, 2-4 May. W.W.F. Pakistan, Lahore, Pakistan, pp. 41.

Reinert, J. (1958) Uber die Kontrolle der Morphogenese and die Induktion Von Adventivembryonen and Gewebek Ulturen aus Korotten. Planta. 53: 318-333.
Rout, G. R. (2005) Micropropagation of Clitoria ternatea Linn. In Vitro Cellular \& Developmental Biology BiologyPlant, 41(4): 516-519.

Schippmann, U., Leaman, D.J. and Cunningham, A.B. (2002) Impact of cultivation and gathering of medicinal plants on biodiversity: global trends and issues. InterDepartment Working Group on Biology Diversity for Food and Agriculture, Food and Agricultural Organisation of the United Nations, Rome, Italy.

Sharma, N \& Chandel, K. P. S (1992) Effects of ascorbil acid on axillary shoot induction in Tylophora indica (Burm.F.) Merill, Plant Cell Tissue Organ Culture, 29: 109.

Shiva, V. (1996) Protecting our biological and intellectual heritage in the age of biopiracy. The Research Foundation for Science, Technology and Natural Resources Policy, New Delhi, India.

Sood, H. and Chauhan, H. S. (2009) Development of a low cost micropropagation technology for an endangered medicinal herb (Picorhiza kurroa) of North-Western Himalayas. Journal of Plant Sciences, 1-11.

Steward, F.C., Maper, M.O. and Smith, J. (1958). Growth and organized development of cultured cell 11 . Organization in culture grown from freely suspended cells. Amer. J. Bot. 45: 705-708.

Thorpe, T.A. and Patel, K.R. (1984) Clonal propagation: Adventitious buds. In : Vasil, I.K.(Ed.). Cell Culture and Somatic Cell Genetic in Plants. Vol. 1. Academic Press, New York, pp.49-60.

Toledo, V. M. (1995) New paradigms for a new ethnobotany: reflections on the case of Mexico. In: Schultes, R. E. and. Von Reis, S. (Eds.). Ethnobotany: evolution of a discipline. Chapman and Hall, London, UK. pp. $75-88$.

Tommasi, F. and Scaramuzzi, F. (2004) In vitro propagation of Ginkgo biloba by using various bud cultures. Biologia Plantarum. 48(2): 297-300.

Vadodaria, H. K., Samantaray, S. and Maiti, S. (2007) Micropropagation of Glycyrrhiza glabra Linn. An important medicinal plant. Journal of Cell and Tissue Research. 7(1): 921-926.

Xiao, P.G. and Yong, P. (1998) Ethnopharmacology and research on medicinal plants in China. In : Prendergast, H.D.V. Etkin, N.L. Harris, D.R. and Houghton, P.J. (Eds.). Plants for food and medicine. Proc. Joint Conference of the Society for Economic Botany and the International Society for Ethnopharmacology, London, 1-6 July 1996, Royal Botanic Gardens, Kew, UK. pp. 31-39. 